\title{
Two Isocoumarins from Pleurospermum angelicoides
}

\author{
Makio Shibano, ${ }^{a}$ Hideyuki Naito, ${ }^{a}$ Masahiko TAniguchi, ${ }^{a}$ Nian-He Wang, ${ }^{b}$ and Kimiye BABA ${ }^{*}, a$ \\ ${ }^{a}$ Osaka University of Pharmaceutical Sciences; 4-20-1 Nasahara, Takatsuki, Osaka 569-1094, Japan: and ${ }^{b}$ Institute of \\ Botany, Jiangsu Province and Academia Sinica; 210014, Nanjing, China. \\ Received November 9, 2005; accepted January 16, 2006
}

Two new isocoumarins, angelicoins $\mathrm{A}$ and $\mathrm{B}$, were isolated from the roots of Pleurospermum angelicoides, and their structures were established by spectral means.

Key words Pleurospermum angelicoides; Umbelliferae; isocoumarin

The roots of Pleurospermum angelicoides BENTH., “帰葉 稜子芹”, distributed in the Himalaya mountains (3300$4800 \mathrm{~m}$ above the sea level): Yunnan province, China, southern Chibetto, India and Nepal, are a Chinese folk medicine used as an antipyretic and diaphoretic agent in local areas of Yunnan province, China ${ }^{1)}$ and as treatments of typhia and dysentery by the name of "Chipi" in Himalaya. ${ }^{2)}$

In the course of our studies of the chemical constituents of Umbelliferous plants, we have isolated two new isocoumarins, angelicoins A (1) and B (2), in addition to thirteen known coumarins, 8-geranyl-7-hydroxycoumarin, ${ }^{3)}$ osthol, psoralen, bergapten, xanthotoxin, imperatorin, phellopterin, 8-geranyloxypsoralen, heraclenin, 8-(3-chloro-2hydroxy-3-methylbutoxy) psoralen, heraclenol, marmesin, marmesinin, and three polyacetylens, falcarindiol, 9,17octadecadien-12,14-diyne-1,11,16-triol-1-acetale, 9,17-octadecadien-12,14-diyen-1,11,16-triol and ferulic acid. This paper is concerned with the structural elucidation of compounds 1 and 2 (Fig. 1).

The roots of $P$. angelicoides, collected from a mountainous area of Yunnan Province, China, were extracted five times with $\mathrm{MeOH}$. The $\mathrm{MeOH}$ extract was subjected to a combination of silica gel and Sephadex LH-20 chromatography in the various solvent systems to afford compounds $\mathbf{1}$ and $\mathbf{2}$.

Compound $\mathbf{1}$ was isolated as a white amorphous powder, after purification by preparative TLC. Its molecular composition was found to be $\mathrm{C}_{15} \mathrm{H}_{18} \mathrm{O}_{4}$ by $\mathrm{HR}$ mass spectroscopy. The UV spectrum showed absorption maxima at 365.5, $274.5 \mathrm{~nm}$, and the IR spectrum showed absorption bands at $3182,1637,1616$, and $1503 \mathrm{~cm}^{-1}$, suggesting the presence of a hydroxyl, an aromatic ring and unsaturated lactone. The ${ }^{1} \mathrm{H}$ - and ${ }^{13} \mathrm{C}-\mathrm{NMR}$ spectra (Table 1 ) exhibited signals assignable to a 3-methyl-6,7,8-trisubstituted-3,4-dihydroisocoumarin ring $\left(\delta_{\mathrm{H}} 6.20 \mathrm{~s}, 4.65 \mathrm{~m}, 2.82 \mathrm{~m}, 1.50 \mathrm{~d} ; \delta_{\mathrm{C}} 170.3\right.$, $161.7,161.2,138.6,112.5,106.4,101.4,75.6,34.6,20.7)$ and a chelated hydroxyl group $\left(\delta_{\mathrm{H}} 11.54 \mathrm{~s}\right)$. These spectral data were closely related to those of coriandrone $\mathrm{D}^{4)}$ isolated from the whole plant of Coriandrum sativum (Umbelliferae), except for the presence of signals assignable to a 3-methyl-2-
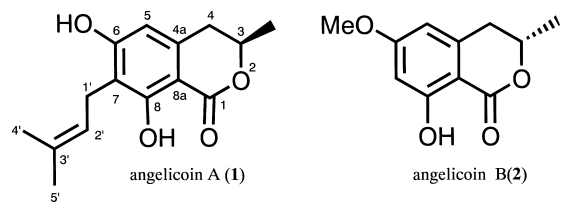

Fig. 1. Structures of $\mathbf{1}$ and $\mathbf{2}$ butenyl group $\left(\delta_{\mathrm{H}} 5.26 \mathrm{~m}, 3.42 \mathrm{~d}, 1.82 \mathrm{~d}, 1.76 \mathrm{~d} ; \delta_{\mathrm{C}} 135.8\right.$, $121.0,25.8,21.8,17.9)$ and a hydroxyl group $\left(\delta_{\mathrm{H}} 6.20 \mathrm{~s}\right)$, instead of signals due to a 2-acetoxy-3-hydroxy-3-methylbutyl group and a methoxy group. The location of each functional group was determined by analyses of ${ }^{1} \mathrm{H}-{ }^{1} \mathrm{H}$ correlated spectroscopy $\left({ }^{1} \mathrm{H}-{ }^{1} \mathrm{H}\right.$ COSY $)$, heteronuclear multiple quantum coherence (HMQC), heteronuclear multiple-bond coherence (HMBC) and nuclear Overhauser effect spectroscopy (NOESY) spectra of 1, as shown in Fig. 2.

The absolute configuration at C-3 was concluded to be $R$ form based on the fact that the circular dichroic (CD) spectrum of 1 showed a negative Cotton effect ascribed to the Kabsorption band at $272 \mathrm{~nm}(\Delta \varepsilon-1.16){ }^{4,5)}$

Compound 2 was isolated as a colorless amorphous powder. Its molecular composition was found to be $\mathrm{C}_{11} \mathrm{H}_{12} \mathrm{O}_{4}$ by

Table 1. ${ }^{1} \mathrm{H}$ - and ${ }^{13} \mathrm{C}$-NMR Data for $\mathbf{1}$ and $\mathbf{2}$ in $\mathrm{CDCl}_{3}$

\begin{tabular}{|c|c|c|c|c|}
\hline & \multicolumn{2}{|c|}{${ }^{1} \mathrm{H}$} & \multicolumn{2}{|c|}{${ }^{13} \mathrm{C}$} \\
\hline & 1 & 2 & 1 & 2 \\
\hline 1 & - & - & 170.3 & 169.8 \\
\hline 3 & $4.65 \mathrm{~m}$ & $4.68 \mathrm{~m}$ & 75.6 & 75.5 \\
\hline 4 & $2.82 \mathrm{~m}$ & $2.87 \mathrm{~m}$ & 34.6 & 34.9 \\
\hline $4 a$ & - & - & 138.6 & 140.9 \\
\hline 5 & $6.20^{a)} \mathrm{s}$ & $6.25 \mathrm{~m}$ & 106.4 & 106.2 \\
\hline 6 & - & - & 161.7 & 165.8 \\
\hline 7 & - & $6.37 \mathrm{~d}(2.3)$ & 101.4 & 99.4 \\
\hline 8 & - & - & 161.2 & 164.6 \\
\hline $8 \mathrm{a}$ & - & - & 112.5 & 101.6 \\
\hline 3-Me & $1.50 \mathrm{~d}(6.2)$ & $1.51 \mathrm{~d}(6.2)$ & 20.7 & 20.7 \\
\hline $1^{\prime}$ & $3.42 \mathrm{~d}(7.3)$ & - & 21.8 & - \\
\hline $2^{\prime}$ & $5.26 \mathrm{~m}$ & - & 121.0 & - \\
\hline $3^{\prime}$ & - & - & 135.8 & - \\
\hline $4^{\prime}$ & $1.82 \mathrm{~d}(0.9)$ & - & 17.9 & - \\
\hline $5^{\prime}$ & $1.76 \mathrm{~d}(1.4)$ & - & 25.8 & - \\
\hline $6-\mathrm{OH}$ & $6.20^{a)} \mathrm{s}$ & - & - & - \\
\hline 6-OMe & - & $3.83 \mathrm{~s}$ & - & 55.6 \\
\hline $8-\mathrm{OH}$ & $11.54 \mathrm{~s}$ & $11.25 \mathrm{~s}$ & - & - \\
\hline
\end{tabular}

Chemical shifts are in $\delta$ values, followed by multiplicities and $J$ values (in $\mathrm{Hz}$ ). a) Overlapping signals.

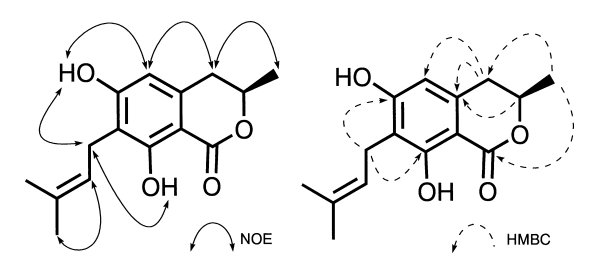

Fig. 2. The Main HMBC and NOE Correlations of $\mathbf{1}$ 
HR mass spectroscopy. The UV and IR spectral data of $\mathbf{2}$ indicated that $\mathbf{2}$ is an analogous isocoumarin of $\mathbf{1}$. The ${ }^{1} \mathrm{H}$ - and ${ }^{13} \mathrm{C}$-NMR spectra (Table 1 ) were very similar to those of $\mathbf{1}$, except for the presence of a methoxyl group $\left(\delta_{\mathrm{H}} 3.83 \mathrm{~s}, \delta_{\mathrm{C}}\right.$ 55.55) and two aromatic protons coupled at the meta position $\left(\delta_{\mathrm{H}} 6.25 \mathrm{~m}, 6.37 \mathrm{~d}\right)$, and the lack of signals due to a hydroxy group and a 3-methyl-2-butenyl group of $\mathbf{1}$. The HMBC and NOESY spectra of $\mathbf{2}$ made its planar structure clear.

The absolute configuration of $\mathrm{C}-3$ was confirmed to be $S$ by CD spectral data (K-absorption bond: $267 \mathrm{~nm}(\Delta \varepsilon$ +0.96 ), positive Cotton effect). Therefore, 2 was an enantiomer of 6-methoxymellein.

\section{Experimental}

General ${ }^{1} \mathrm{H}$ - and ${ }^{13} \mathrm{C}-\mathrm{NMR}$, distortionless enhancement by polarization transfer (DEPT), HMQC, and HMBC spectra were recorded on a Varian UNITY INOVA-500 spectrometer, operating at $500 \mathrm{MHz}$ for proton and $125 \mathrm{MHz}$ for carbon, with tetramethylsilane (TMS) as an internal standard. HR-EI-MS spectra were obtained using a Hitachi M-4100H $(70 \mathrm{eV})$ mass spectrometer. UV and IR spectra were recorded on a Shimadzu UV-2100 and a Perkin Elmer FT-IR 1720 spectrophotometer, respectively. CD spectra were recorded on a JASCO J820 digital polarimeter. Column chromatography was performed using Fuji silycia silica gel PSQ100B, Merck silica gel 60H, YMC GEL ODS-A 60-400/230 and Sephadex LH-20. TLC and prep.TLC was carried out on Merck Silica gel $\mathrm{F}_{254}$ plates $(0.25 \mathrm{~mm})$ and Whatmann silica gel 150A PLK 5F (1 mm). Spots and bands were detected by UV irradiation $(254,365 \mathrm{~nm})$.

Plant Material Air-dried roots of P. angelicoides $(1.23 \mathrm{~kg})$ were collected from plants grown in Lijiang, Yunnan Province, China, in September 2000. Voucher specimens are deposited in the Institute of Botany, Jiangsu Province, and Academia Sinica, Nanjing, China. The plant was identified by one (N.W.) of the authors.

Extraction and Isolation The roots were chopped into small pieces and extracted with $\mathrm{MeOH}$ (each $31 \times 5$ ) under reflux. The $\mathrm{MeOH}$ extracts were concentrated to dryness in vacuo. The residue $(140 \mathrm{~g})$ was subjected to column chromatography on silica gel, and eluted successively with hexane-EtOAc $(3: 1 \rightarrow 1: 3)$ and $\mathrm{CH}_{2} \mathrm{Cl}_{2}-\mathrm{MeOH}(10: 1 \rightarrow 3: 1)$ solvent systems with increasing polarity to afford 15 fractions (fr.) [fr. 1 (3.6g), fr. 2 $(2.0$ g), fr. $3(4.3 \mathrm{~g})$, fr. $4(14.5 \mathrm{~g})$, fr. $5(7.0 \mathrm{~g})$, fr. $6(1.2 \mathrm{~g})$, fr. $7(0.15 \mathrm{~g})$, fr. 8 (1.2 g), fr. 9 (6.4 g), fr. $10(2.5 \mathrm{~g})$, fr. $11(2.3 \mathrm{~g})$, fr. $12(1.1 \mathrm{~g})$, fr. $13(0.2 \mathrm{~g})$, fr.
$14(0.2 \mathrm{~g})$, fr. $15(1.2 \mathrm{~g})]$. Each fraction was respectively rechromatographed on silica gel with $\mathrm{CH}_{2} \mathrm{Cl}_{2}$ and $\mathrm{CH}_{2} \mathrm{Cl}_{2}-\mathrm{MeOH}$ solvent systems to give 17 compounds, including 1 and 2 [fr. 1: falcarindiol $(976.7 \mathrm{mg})$, fr. 2: angelicoin B (7.6 mg), falcarindiol (2.1 g), fr. 3: osthol (2.4 g), psoralen (17.6 mg), angelicoin A $(2.6 \mathrm{mg}), \quad 8$-geranyloxypsoralen $(7.7 \mathrm{mg})$, imperatorin $(92.4 \mathrm{mg})$, bergapten $(5.6 \mathrm{mg}), 8$-geranyl-7-hydroxycoumarin $(1.3 \mathrm{~g})$, phellopterin $(37.5 \mathrm{mg})$, fr. 4: angelicoin A $(13.8 \mathrm{mg}), 8$-geranyl-7-hydroxycoumarin $(966.0 \mathrm{mg})$, xanthotoxin $(14.2 \mathrm{mg}), 9,17$-octadecadien-12,14diyne-1,11,16-triol-1-acetale $+9,17$-octadecadien-12,14-diyne-1,11,16-triol $(642.1 \mathrm{mg})$, fr. 5 : heraclenin $(49.3 \mathrm{mg})$, fr. 6 : heraclenin $(15.7 \mathrm{mg}), 8-(3-$ chloro-2-hydroxy-3-methylbutoxy) psoralen $(10.7 \mathrm{mg})$, fr. 8 ferulic acid $(40.0 \mathrm{mg})$, fr. 9: heraclenol $(155.2 \mathrm{mg})$, fr. 10: heraclenol $(17.2 \mathrm{mg})$, fr. 13: marmesin $(3.2 \mathrm{mg})$, fr. 14: marmesin $(9.8 \mathrm{mg})$, fr. 15 : marmesin $(2.7 \mathrm{~g})$.

Angelicoin A (1): White amorphous powder, HR-EI-MS: $\mathrm{m} / \mathrm{z}$ 262.1205 $[\mathrm{M}]^{+}$(Calcd for $\left.\mathrm{C}_{15} \mathrm{H}_{18} \mathrm{O}_{4}: 262.1204\right)$, UV $\lambda_{\max }(\mathrm{MeOH}) \mathrm{nm}(\log \varepsilon): 367.5$ (2.24), 274.5 (4.17), 220.5 (4.41), IR (KBr) cm $\mathrm{cm}^{-1}: 3182,1637,1616,1503$, $\mathrm{CD}\left(c=3.8 \times 10^{-5}, \mathrm{MeOH}\right) \Delta \varepsilon(\mathrm{nm}):-1.16(272),+0.77(247),-2.37$ (228), $[\alpha]_{\mathrm{D}}^{20}-37.1^{\circ}(c=0.5, \mathrm{MeOH}) .{ }^{1} \mathrm{H}-$ and ${ }^{13} \mathrm{C}-\mathrm{NMR}$ data are shown in Table 1.

Angelicoin B (2): White amorphous powder, HR-EI-MS: $m / z 208.0738$ $[\mathrm{M}]^{+}$(Calcd for $\left.\mathrm{C}_{11} \mathrm{H}_{12} \mathrm{O}_{4}: 208.0734\right)$, UV $\lambda_{\max }(\mathrm{MeOH}) \mathrm{nm}(\log \varepsilon): 300.0$ (3.69), 266.5 (4.05), 214.5 (4.24), IR (KBr) cm $\mathrm{cm}^{-1}: 1665,1630,1580, \mathrm{CD}$ $\left(c=4.8 \times 10^{-6}, \mathrm{MeOH}\right) \Delta \varepsilon(\mathrm{nm}):+0.96(267),-0.35(249),+1.27(233)$, $[\alpha]_{\mathrm{D}}^{20}+31.5^{\circ}(c=0.5, \mathrm{MeOH}) .{ }^{1} \mathrm{H}-$ and ${ }^{13} \mathrm{C}-\mathrm{NMR}$ data are shown in Table 1.

Acknowledgements The authors are grateful to Mr. K. Minoura for NMR spectral recordings and to Mrs. M. Fujitake for mass spectra recordings at Osaka University of Pharmaceutical Sciences. This work was partially supported by NSFC (project 30270097), China.

\section{References}

1) "Flora Reipublicae Popularis Sinicae," Vol. 55 (1), Science Press, China, 1979, pp. 152-153.

2) Unuyal S. K., Awasthi A., Rawat G. S., Curr. Sci., 82, 1246-1252 (2002).

3) Rashid M. A., Armstrong J. A., Gray A. I., Waterman P. G., Z. Naturforsch., 47b, 284-287 (1992).

4) Taniguchi M., Yanai M., Xiao Y. Q., Kido T., Baba K., Phytochemistry, 42, 843-846 (1996).

5) Krohn K., Bahramsari R., Florke U., Ludewig K., Kliche-Spory C., Michel A., Aust. H. J., Draeger S., Schulz B., Antus S., Phytochemistry, 45, 313-320 (1997). 